\title{
COMPARISON OF EDENTULOUS WOMEN AND DENTATE WOMEN IN TERMS OF MANDIBULAR ALVEOLAR RIDGE HEIGHT REVIEWED USING PANORAMIC RADIOGRAPHY
}

\author{
Cek Dara Manja ${ }^{1}$, Shanaya Abkharina ${ }^{2}$ \\ ${ }^{1}$ Department of Dentomaxillofacial Radiology, Faculty of Dentistry, University of Sumatera Utara, Medan City ${ }^{2}$ Student of \\ Faculty of Dentistry, University of Sumatera Utara, Medan City \\ E-mail: cekdaramanja@yahoo.co.id
}

\begin{abstract}
When tooth loss occurs, the absence of mechanical stimulus on alveolar ridge, the decline occurred because the height of the alveolar ridge undergoes a slow physiological resorption. The purpose of this research is to know the difference and the average height of the mandibular alveolar ridge in edentulous and dentate women using panoramic radiography. The method of this research is an analytical method with cross-sectional approach. Total sample of 40 women, edentulous and dentate has been measured. Measurements were made by measuring the distance between the lowest point of mandibular and alveolar crest mandibular on the incisor point, right and left premolar, right and left molar. Statistical test is done using independent $t$ test. The results showed that the average value of a dentate women sample is greater than edentulous. Average value obtained by the dentate sample is greatest in right premolar point by $29,53 \mathrm{~mm} \pm 2,36 \mathrm{~mm}$ and the smallest at the left molar point by $25,48 \mathrm{~mm} \pm 2,41 \mathrm{~mm}$. Average value obtained by the edentulous sample is greatest in right molar point by $22,26 \mathrm{~mm} \pm 3,67 \mathrm{~mm}$ and the smallest at the left premolar point by $21,21 \mathrm{~mm} \pm 4,79 \mathrm{~mm}$. It can be concluded that there is a significant difference in the height of the mandibular alveolar ridge on edentulous sample and dentate in everypoint of measurement. The average height of the mandibular alveolar ridge in edentulous sample is $21,78 \mathrm{~mm} \pm 3,88$ $\mathrm{mm}$ and the dentate sample is $27,71 \mathrm{~mm} \pm 2,77$
\end{abstract}

Keywords: Mandibular alveolar ridge, dentate women, edentulous women, panoramic radiography

\section{INTRODUCTION}

One of the structure that can be seen in radiography panoramic is alveolar ridge. ${ }^{1}$ After the loss of teeth, mechanical force in alveolar ridge will reduced and this causes the height of the alveolar ridge to reduced. ${ }^{2}$ The rate of resorption in alveolar ridge differs between maxilla and mandibular. In mandible, the rate of resorption is three to four times more than maxilla because the maxilla's bone is wider than mandibular bone, thus the force received by mandibular is bigger. ${ }^{3}$ The resorption of alveolar ridge in the anterior region in maxilla in more to backwards and upwards and the resorption rate is progressive. In the posterior region in maxilla, the resorption is upwards and inwards and this causes the sides of the alveolar to be smaller in every progressive manner. Meanwhile, in the anterior and posterior region of mandibular the alveolar ridge has a resorption forwards and downwards. ${ }^{4}$

Mandibular alveolar ridge's height in dentate women and edentulous women can be measured by calculating the height of the alveolar ridge through panoramic radiography. Measurements were made by measuring the distance between the lowest point of the mandibular and alveolar crest mandibular on the incisor point, right and left premolar, right and left molar. The purpose of this research is to know the difference and the average height of the mandibular alveolar ridge in edentulous and dentate women using panoramic radiography.

\section{MATERIALS AND METHODS}

This research is an analytical method using crosssectional. This research performed in dental radiology installation and prosthdontic clinic, dental and mouth hospital, University of Sumatera Utara. The sample of this research were all women patients and students in the prosthodontic clinic of University of Sumatera Utara. This research uses 40 samples, 20 dentate and 20 edentulous. Samples must meet the following criteria. Inclusion criteria were: (1) the edentulous group, has a full edentulous jaw and menopause. (2) The dentate group, has a dentate jaw entirely and haven't menopause. Exclusion criteria were: (1) have a diagnosed history of cysts, tumours on the jaw and suffering from systemic disease manifested on the bones. (2) Rejects request to become the sample. The tools used in this research is panoramic radiography Instrumentarium type OC 200 D 1-4-1, cliniview software version 10.1.2, mouth mirror, dental tweezers, probe, nierbekken, stationery and the sensors. The materials used are notepad, alcohol $70 \%$ and cotton.

Measurements were made by measuring the distance between the lowest point of the mandibular and alveolar crest mandibular. Whereas dentate patients is 1.2 $\mathrm{mm}$ from cementoenamel junction. On the dentate jaw, a straight line is taken from the inferior point of mandibular (line $\mathrm{X}$ ). Then a vertical straight line with the line $\mathrm{X}$ is measured on the midline point $(\mathrm{P})$, distal first premolar $(\mathrm{Q})$ and distal first molar (R). The other line is taken $10 \mathrm{~mm}$ above line $\mathrm{X}$ to calculate the proportion horizontal distance of first premolar and molar.

In edentulous jaw, a vertical straight line is measured on midline $(\mathrm{P})$ guided by the point of genial tubercle, horizontal distance from the middle line to first premolar $(\mathrm{Q})$ and first molar $(\mathrm{R})$ is guided by calculating the proportion from dentate jaw sample and the average is taken. The formula is as shown as below: 
Cek Dara: Comparison of edentulous women and dentate

a long line from midline to first premolar $(B)$

$\frac{\text { and first molar }(C)}{\text { a long line from midline to the boundary }} \times 100 \%$ of posterior ramus $(A)$

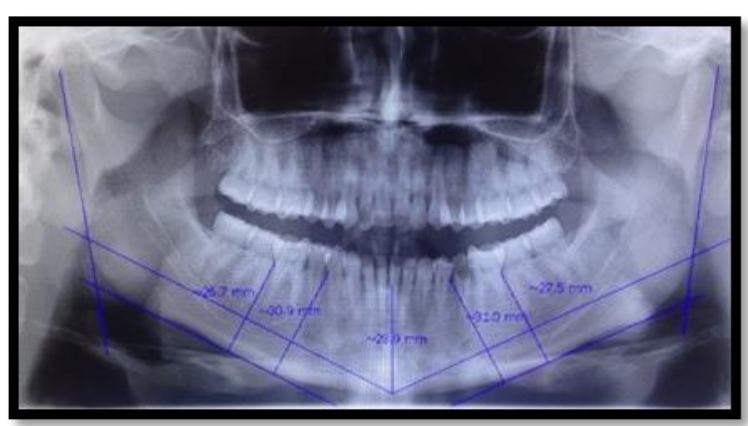

Figure 1. Measurement of maxillary alveolar ridge height on dentate women (personal documentation)

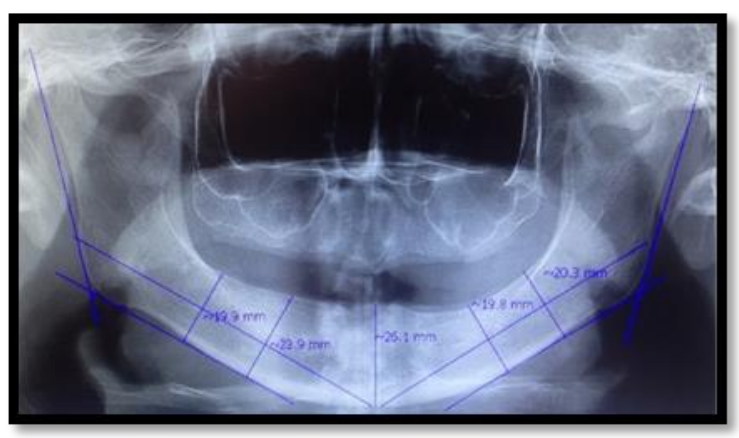

Figure 2. Measurement of maxillary alveolar ridge height on edentulous women (personal documentation)

The average height of the mandibular alveolar ridge were done using Shapiro Wilk normality test. When the distribution results were obtained normal, data differences were tested using independent $t$ test. It is done using a computer program called SPSS 20.

This study was approved by Health Research Ethical Committee of North Sumatera dengan nomor 60/TGL/KEPK FK USU-RSUP HAM/2017.

\section{RESULTS AND DISCUSSION}

Table 1. Result shows average value measurement on the height of the mandibular alveolar ridge in incisor, right premolar and molar point, left premolar and molar point

\begin{tabular}{cccccc}
\hline & Sample & $\mathrm{N}$ & Mean & $\begin{array}{c}\text { Std. } \\
\text { Deviation }\end{array}$ & $\begin{array}{c}\text { Std. Error } \\
\text { Mean }\end{array}$ \\
\hline \multirow{2}{*}{$\begin{array}{c}\text { Insisivus } \\
\text { (midline })\end{array}$} & Edentulous & 20 & 21.79 & 3.84 & .86 \\
\cline { 2 - 6 } & Dentate & 20 & 28.35 & 1.74 & .39 \\
\hline \multirow{2}{*}{$\begin{array}{c}\text { Right } \\
\text { Premolar }\end{array}$} & Edentulous & 20 & 21.78 & 4.31 & .96 \\
\cline { 2 - 6 } & Dentate & 20 & 29.53 & 2.36 & .53 \\
\hline Right Molar & Edentulous & 20 & 22.25 & 3.66 & .82 \\
\cline { 2 - 6 } & Dentate & 20 & 26.09 & 2.05 & .46 \\
\hline \multirow{2}{*}{ Left Premolar } & Edentulous & 20 & 21.21 & 4.78 & 1.07 \\
\cline { 2 - 6 } & Dentate & 20 & 29.13 & 2.64 & .59 \\
\hline \multirow{2}{*}{ Left Molar } & Edentulous & 20 & 21.97 & 2.87 & .64 \\
\cline { 2 - 6 } & Dentate & 20 & 25.48 & 2.41 & .54 \\
\hline
\end{tabular}

Table 2. Results of measurements of the height of the mandibular alveolar ridge on edentulous and dentate women

\begin{tabular}{ccccc}
\hline Sampel & Min & Max & Mean & Std. Deviation \\
\hline Edentulous & 12.50 & 32.50 & 21.80 & 3.88 \\
Dentate & 20.60 & 34.10 & 27.71 & 2.76 \\
\hline
\end{tabular}

Tabel 3. Shapiro wilk test data

\begin{tabular}{|c|c|c|c|c|}
\hline & \multirow{2}{*}{ Sample } & \multicolumn{3}{|c|}{ Shapiro-Wilk } \\
\hline & & Statistic & Df & Sig. \\
\hline \multirow{2}{*}{$\begin{array}{l}\text { Insisivus } \\
\text { (midline) }\end{array}$} & Edentulous & .966 & 20 & .664 \\
\hline & Dentate & .945 & 20 & .295 \\
\hline \multirow{2}{*}{$\begin{array}{c}\text { Right } \\
\text { Premolar }\end{array}$} & Edentulous & .982 & 20 & .954 \\
\hline & Dentate & .953 & 20 & .421 \\
\hline \multirow[t]{2}{*}{ Right Molar } & Edentulous & .941 & 20 & .247 \\
\hline & Dentate & .940 & 20 & .243 \\
\hline \multirow[t]{2}{*}{ Left Premolar } & Edentulous & .965 & 20 & .638 \\
\hline & Dentate & .963 & 20 & .608 \\
\hline \multirow[t]{2}{*}{ Left Molar } & Edentulous & .970 & 20 & .759 \\
\hline & Dentate & .961 & 20 & .556 \\
\hline
\end{tabular}

Table 4. The test data difference on the height of mandibular alveolar ridge values using independent $t$ test on incisor teeth

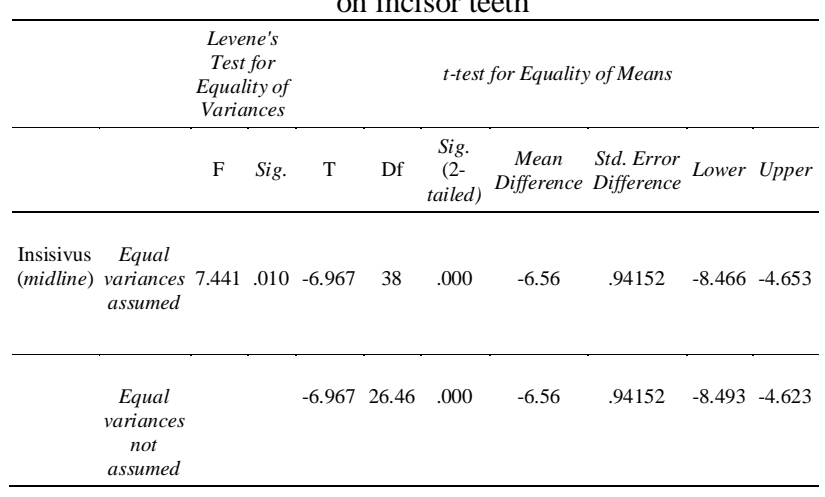

Table 5. The test data difference on the height of mandibular alveolar ridge values using independent $t$ test on right premolar teeth

\begin{tabular}{|c|c|c|c|c|c|c|c|c|c|c|}
\hline & & $\begin{array}{r}\text { Leven } \\
\text { for Eq } \\
\text { Var }\end{array}$ & $\begin{array}{l}\text { 's Test } \\
\text { ality of } \\
\text { ances }\end{array}$ & & & & -test for Equa & ality of Mean & & \\
\hline & & $\mathrm{F}$ & Sig. & $\mathrm{T}$ & Df & $\begin{array}{c}\text { Sig. } \\
(2- \\
\text { tailed })\end{array}$ & $\begin{array}{c}\text { Mean } \\
\text { Difference }\end{array}$ & $\begin{array}{l}\text { Std. Error } \\
\text { Difference }\end{array}$ & Lower & Upper \\
\hline Right & $\begin{array}{c}\text { Equal } \\
\text { variances } \\
\text { assumed }\end{array}$ & 2.992 & .092 & -7.061 & 38 & .000 & -7.755 & 1.098 & -9.978 & -5.531 \\
\hline & $\begin{array}{c}\text { Equal } \\
\text { variances } \\
\text { not } \\
\text { assumed }\end{array}$ & & & -7.061 & 29.49 & .000 & -7.755 & 1.098 & -9.999 & -5.510 \\
\hline
\end{tabular}


Table 6. The test data difference on the height of mandibular alveolar ridge values using independent $t$ test on right molar teeth

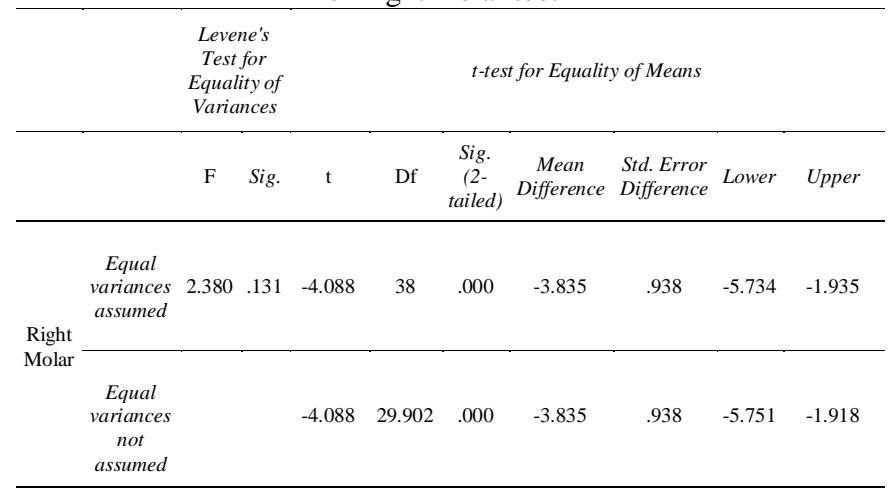

Table 7. The test data difference on the height of mandibular alveolar ridge values using independent $t$ test on left premolar teeth

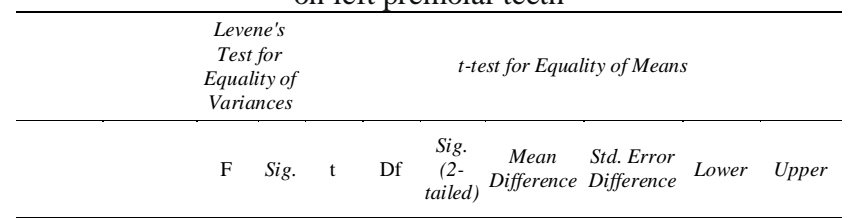

\begin{tabular}{|c|c|c|c|c|c|c|c|c|c|}
\hline \multirow{2}{*}{$\begin{array}{l}\text { Left } \\
\text { premolar }\end{array}$} & $\begin{array}{c}\text { Equal } \\
\text { variances } \\
\text { assumed }\end{array}$ & 3.983 .053 & $6.483^{-}$ & 38 & . 000. & -7.920 & 1.222 & -10.392 & -5.450 \\
\hline & $\begin{array}{c}\text { Equal } \\
\text { variances } \\
\text { not } \\
\text { assumed }\end{array}$ & & 6.483 & 9.57 & .000 & -7.925 & 1.222 & -10.423 & -5.426 \\
\hline
\end{tabular}

Table 8 . The test data difference on the height of mandibular alveolar ridge values using independent $t$ test on left molar teeth

\begin{tabular}{|c|c|c|c|c|c|c|c|c|c|c|}
\hline & & \multicolumn{2}{|c|}{$\begin{array}{l}\text { Levene's Test } \\
\text { for Equality } \\
\text { of Variances }\end{array}$} & \multicolumn{7}{|c|}{ t-test for Equality of Means } \\
\hline & & $\mathrm{F}$ & Sig. & $\mathrm{T}$ & Df & $\begin{array}{c}\text { Sig. } \\
(2- \\
\text { tailed })\end{array}$ & $\begin{array}{c}\text { Mean } \\
\text { Difference }\end{array}$ & $\begin{array}{l}\text { Std. Error } \\
\text { Difference }\end{array}$ & Lower & Upper \\
\hline \multirow{2}{*}{$\begin{array}{l}\text { Left } \\
\text { molar }\end{array}$} & $\begin{array}{c}\text { Equal } \\
\text { variances } \\
\text { assumed }\end{array}$ & .401 & .531 & -4.179 & 38 & .000 & -3.505 & .838 & -5.202 & -1.807 \\
\hline & $\begin{array}{c}\text { Equal } \\
\text { variances } \\
\text { not assumed }\end{array}$ & & & -4.179 & 36.91 & .000 & -3.505 & .838 & -5.204 & -1.805 \\
\hline
\end{tabular}

The results showed the average value of the height of the mandibular alveolar ridge is greater in dentate woman than edentulous woman at each of the measurement point. At the right molar teeth, the average value is greater in dentate women was $26,09 \mathrm{~mm} \pm 2,05$ $\mathrm{mm}$, compared with edentulous woman $22,26 \mathrm{~mm} \pm 3,67$ $\mathrm{mm}$. At the left molar teeth, the average value is greater in dentate women was $25,48 \mathrm{~mm} \pm 2,41 \mathrm{~mm}$, compared with edentulous women $21,97 \mathrm{~mm} \pm 2,87 \mathrm{~mm}$. At the right premolar teeth, the average value is greater in dentate women $(29,53 \mathrm{~mm} \pm 2,36 \mathrm{~mm})$, compared to edentulous women $(21,78 \mathrm{~mm} \pm 4,31 \mathrm{~mm})$. At the left premolar teeth, the average value is greater in dentate women $(29,13 \mathrm{~mm}$ $\pm 2,64 \mathrm{~mm})$, compared with edentulous women $(21,21 \mathrm{~mm}$ $\pm 4,79 \mathrm{~mm}$ ). At the insisor tooth (midline), the average value is greater in dentate women $(28,35 \mathrm{~mm} \pm 1,74 \mathrm{~mm})$, compared to edentulous woman ( $21,79 \mathrm{~mm} \pm 3,83 \mathrm{~mm}$ ). These results are in accordance with the research of Panchbhai (2013) in India ${ }^{5}$ and the research of Canger et al (1995) in Turkey. ${ }^{6}$ In whole, the average value of mandibular alveolar ridge in dentate women is greater than edentulous women. The average height of the mandibular alveolar ridge in edentulous women is $21,78 \mathrm{~mm} \pm 3,88 \mathrm{~mm}$ and dentate woman is $27,71 \mathrm{~mm} \pm 2,77 \mathrm{~mm}$.

In edentulous jaw, does not get enough mechanical stimulation and the metabolism of the bone can be interrupted. ${ }^{7}$ The decrease of mechanical stimulation cause reduced salivary flow production. Its function to inform osteocytes start metabolism and caused the occurrence stimulation of osteoclasts and osteoblasts thus causing the resorption in the alveolar ridge which causes the decrease in the height of the mandibular alveolar ridge. ${ }^{8}$

The results of this study shows a difference of mandibular alveolar ridge between regions, anterior point of incisor has the highest value and the point of molar has the smallest value. This is in accordance with the research of Panchbhai (2013) on India ${ }^{5}$ and the research of Liang et al (2014) in the Korea. ${ }^{6}$ It can be due to several factors. At anterior region of mandibular there is genial muscles, such as geniohyoid and genioglossus. This muscle strength protects the anterior region of faster resorption. At posterior region, the height of the alveolar ridge in the lowest normal state is located on the posterior region which is the molar, followed by premolar and then followed by the highest in the anterior region in the curve of spee. ${ }^{9}$

Physiologically, for menopause women, there are hormonal and mucoskeletal changes. This lead to a decrease in estrogen levels and an increase in alveolar bone resorption. For menopause women, there is a disturbance in endocrine to handle the process of bone remodeling which causes instability of the activity of osteblast osteoclast. This causes the mass of the bone to drop in total. This is in accordance with the research of Kordatzis et al (2003), which got the result of the resorption of mandibular alveolar ridge in women is two times more than men. The length of a woman's menopause effects the decrease in bone density which also causes a decrease in the height of the maxillary alveolar ridge. ${ }^{10}$

Panoramic Radiograph is used for a support in the field of dentistry because it can give a picture of the tooth and its supporting structures both in the maxilla or mandibular. Panoramic radiograph is also used as a diagnostic tool in planning treatment using implants. The design of the implant that can be used is endoosseous implants with a diameter of $3,75 \mathrm{~mm}$ and the length varies between $7 \mathrm{~mm}, 10 \mathrm{~mm}, 13 \mathrm{~mm}$ and 15 mm. Fixing of implants performed when the sides are quite wide and the distance between the implant and the mental foramen and canal mandibular is $2 \mathrm{~mm} .{ }^{11}$

This is because the panoramic radiography technique has enlarged images of the originals. Distortion on panoramic radiography is unavoidable because of the object shadow in film, projection-related structure that varies in some individuals. Fixing of the wrong implants in the upper jaw, can cause damage to anatomical structures at mental foramen and canal mandibular. ${ }^{12}$ This causes the opening mandibular canal thus effecting the nervous of alveolar. This causes the disturbance at neurocensor in mental nervous. This can 
be a permanent or temporary effect in the lower lip and chin. ${ }^{13}$ Because of this the use of radiography dentistry is used to estimate the height of the mandibular alveolar ridge so that the care plan on a edentulous patients can give a good results.

\section{CONCLUSION}

In conclusion, there is a difference in height of the mandibular alveolar ridge significantly in edentulous women and dentate. The average height of the mandibular alveolar ridge in edentulous women is $21,78 \mathrm{~mm} \pm$ $3,88 \mathrm{~mm}$ and dentate woman is $27,71 \mathrm{~mm} \pm 2,77 \mathrm{~mm}$.

\section{ACKNOWLEDGEMENTS}

The authors are grateful to the dental radiology installation at the dental and mouth hospital of the University of Sumatera Utara for providing facility clinics for research work.

\section{REFERENCES}

1. Ghom. Textbook of oral radiology. India : Elsevier; 2008 h. 191-212.

2. D'Souza D. Residual ridge resorption-revisited, oral health care prosthodontics, periodontology, biology, research and systemic condition, Prof. Mandeep Virdi (Ed.), 2012; 15-24.

3. Reich K. Atrophy of the residual alveolar ridge following tooth loss in a historical population. J Oral Diseases 2010; 33: 1-26.

4. Winkler S. Clinical implant site development and alveolar bone resorpsion patterns. $\mathrm{J}$ of Oral Implantology 2002; 28: 226-9.
5. Panchbhai A. Quantitative estimation of vertical heights of maxillary and mandibular jawbones in elderly dentate and edentulous subjects. Special Care In Dentistry (serial online) 2013; 33 (2): 62-9.

6. Canger EM, Celenk P. Radiographic evaluation of alveolar ridge heights of dentate and edentulous patients. Gerodontology 2010; Vol. 29: 17-23.

7. Lee, JK. Bone biology for implant dentistry in atrophic alveolar ridge - theory and practice. Ajou University School of Medicine : Republic of Korea 2011; 17: 413-35.

8. Caetano LJ, Canhao H, Fonseca JE. Osteoblasts and bone formation. Acta Reumatol Port 2007; 132:10310.

9. Guler AU, Sumer M, Sumer P, Bicer I. The evaluation of vertical heights of maxillary and mandibular bones and the location of anatomic landmarks in panoramic radiographs of edentulous patients for implant dentistry. J Oral Rehabil 2005; 32 : 741-6.

10. Kordatzis K, Wright PS, Meijer HJ. Posterior mandibular residual ridge resorption in patients with conventional dentures and implants overdentures. Int J Oral Maxillofac Implants 2003; 18 (3): 47-52.

11. Agency health research and development department of Health. Basic health research report (Riskesdas) Year 2013: Jakarta, 2013: 148-57.

12. Jonah B. Optimization of conventional dental radiography to help the dental implant placement. J dentofacial 2009: Vol 8 (1): 11-6.

13. Marrison A, Chairot M, Kirby S. Mental nerve function after inferior alveolar nerve trasposition for placement of dental implant. Canada: J Dent Assoc, $2002: 46-50$. 